\title{
Autoantibodies to recombinant lipocortin-1 in rheumatoid arthritis and systemic lupus erythematosus
}

\author{
N J GOULDING, ${ }^{1}$ M R PODGORSKI, ${ }^{1}$ N D HALL, ${ }^{1}$ R J FLOWER, \\ J L BROWNING, ${ }^{2}$ R B PEPINSKY, ${ }^{2}$ AND P J MADDISON ${ }^{1}$
}

From the ${ }^{1}$ Bath Institute for Rheumatic Diseases, Pharmacology Group, University of Bath and the ${ }^{2}$ Biogen Research Corp, Cambridge, Massachusetts, USA

SUMMARY Corticosteroids may mediate some of their anti-inflammatory effects via induction of a specific $38 \mathrm{kD}$ protein, lipocortin-1. Autoantibodies to lipocortin-1 were measured by enzyme linked immunosorbent assay (ELISA) in 90 healthy subjects and in 63 patients with rheumatoid arthritis (RA), 36 with systemic lupus erythematosus (SLE), 26 with polymyalgia rheumatica, and 13 with chronic airways disease. Sixteen patients with RA receiving prolonged, high steroid doses (prednisolone $>7.5 \mathrm{mg} /$ day) had raised IgM antilipocortin-1 levels, while 19 patients with RA untreated with steroids had normal levels. This association was independent of disease activity. In SLE, raised antilipocortin-1 levels were associated with active disease and were independent of steroid treatment. Antilipocortin-1 antibody levels were not raised in patients with polymyalgia rheumatica and chronic airways disease. Thus steroid treatment alone appears insufficient to induce antilipocortin-1 antibodies, unless an underlying autoimmune state is also present. In RA, antilipocortin-1 antibodies may impair anti-inflammatory actions of steroids and render some patients 'steroid resistant'.

Corticosteroids are potent anti-inflammatory drugs frequently used in the treatment of a wide range of rheumatic and other disorders. Their mode of action is multifactorial but in general requires the induction of specific genes within the cell nucleus and subsequent formation of new proteins. One such steroid induced protein is lipocortin- $1,{ }^{1}$ a $38 \mathrm{kD}$ molecule originally identified as lipomodulin ${ }^{2}$ or macrocortin. ${ }^{3}$ Lipocortin-1 inhibits phospholipase $A_{2}$ activity in in vitro assays and thus suppresses the generation of phospholipid derived inflammatory mediators, including prostaglandins, thromboxanes, and leucotrienes. ${ }^{4}$ The mechanism by which lipocortin-1 exerts its antiphospholipase $A_{2}$ effect is uncertain, as recent data imply an indirect inhibition of enzyme activity where lipocortin competes with enzyme for its phospholipid substrate. ${ }^{5} \mathrm{~A}$ family of six distinct lipocortin-like proteins has recently been described, with highly conserved sequences. They have

Accepted for publication 1 February 1989.

Correspondence to Professor P J Maddison, Royal National Hospital for Rheumatic Diseases. Upper Borough Walls, Bath BA1 1RL, UK. common calcium and phospholipid binding properties with a conserved fourfold repeat structure, suggesting a common functional element, though the exact nature of this is not yet determined. ${ }^{6}$

Although corticosteroids are frequently used in the treatment of rheumatoid arthritis (RA), systemic lupus erythematosus (SLE), and polymyalgia rheumatica, the clinical observation of high corticosteroid requirements for control of inflammatory disease in some patients has long been recognised. ${ }^{7}$ Furthermore, the 'steroid pseudorheumatism' syndrome in RA may occur with prolonged periods of corticosteroid treatment at doses of prednisolone greater than $7.5 \mathrm{mg} /$ day. ${ }^{8}$ Even with minor reductions of dose, symptoms often worsen and objective synovitis may flare, implying a functional corticosteroid insufficiency in patients receiving prolonged corticosteroid treatment. ${ }^{78}$

Recently, autoantibodies to lipomodulin (lipocortin) have been described in some patients with RA and SLE, ${ }^{9}$ and thus it has been proposed that such autoantibodies may account for apparent 
'steroid resistance' in those patients with RA and SLE requiring high maintenance doses of corticosteroids to control their inflammatory disease. As recombinant lipocortin-1 is now available ${ }^{10}$ this has been used in a solid phase enzyme linked immunosorbent assay (ELISA) system to detect autoantibodies against lipocortin-1 in serum samples from patients with connective tissue diseases and from appropriate controls.

\section{Patients and methods}

PATIENTS AND CONTROLS

One hundred and twenty five patients of the Royal National Hospital for Rheumatic Diseases, and Royal United Hospital, Bath, took part in this prospective cross sectional study. Sixty three had classic or definite $\mathrm{RA}^{11}$ : of these, 19 had never received corticosteroids (RA-NIL), 28 were receiving prednisolone $<7.5 \mathrm{mg} /$ day (RA-LOW), and 16 required prednisolone $>7.5 \mathrm{mg} /$ day (RA$\mathrm{HIGH}$ ), for a period of $>12$ months with at least three unsuccessful attempts to reduce dosage, for control of inflammatory disease (Table 1). Thirty sixㅁ. patients had SLE $^{12}$ : 11 had never received corti-? costeroids (SLE-NIL), 11 were receiving predniso $-\overrightarrow{\vec{c}}$ lone $<7.5 \mathrm{mg} /$ day (SLE/LOW), and 14 required maintenance prednisolone $>7.5 \mathrm{mg} /$ day (SLEHIGH) for disease control (Table 2). Twenty sixe patients had a clinical diagnosis of polymyalgia rheumatica $^{13}$; all were taking corticosteroids, nine a prednisolone doses $>7.5 \mathrm{mg} /$ day. As controls, serum samples from 67 random healthy blood donor $\overrightarrow{0}$ volunteers and 23 healthy elderly subjects, without major medical illness or corticosteroid treatment $\omega_{\omega}$ were also analysed. A comparison group of 130 patients with reversible chronic obstructive airways disease requiring maintenance corticosteroid, $(1050$ receiving high corticosteroid doses) were also -5 studied; these last 10 patients fulfilled criteria fobo 'corticosteroid resistant' asthma (patients whoset forced expiratory volume in one second does nof increase by more than $15 \%$ after a seven day course of at least $20 \mathrm{mg}$ of prednisolone daily). ${ }^{14}$

Table 1 Clinical data for the group with rheumatoid arthritis

\begin{tabular}{|c|c|c|c|}
\hline Variable & $\begin{array}{l}R A-N I L^{*} \\
(n=19)\end{array}$ & $\begin{array}{l}R A-L O W^{*} \\
(n=28)\end{array}$ & $\begin{array}{l}R A-H I G ! \\
(n=16)\end{array}$ \\
\hline Age (years) $\dagger$ & $58(50-66)$ & $68(58-76)$ & $60(50-67)$ \\
\hline Sex distribution $\mathrm{M}: \mathrm{F}$ & $4: 15$ & $5: 23$ & $6: 10$ \\
\hline Disease duration (years) $\dagger$ & $7(2-9)$ & $20(9-25)$ & $19(9-27)$ \\
\hline Erosions (n)† & 17 & 26 & 15 \\
\hline Nodules (n) & 4 & 16 & 12 \\
\hline Seropositive (n) & $1^{\prime \prime}$ & 26 & 15 \\
\hline Extra-articular disease (n) & 5 & 13 & 7 \\
\hline Recent rheumatoid factor level $(\mathrm{IU} / \mathrm{ml}) \dagger$ & $188(60-392)$ & $89(7-251)$ & $134(29-422)$ \\
\hline Active joint areas $\dagger$ & $8(6-12)$ & $5(3-8)$ & $6(2-9)$ \\
\hline Immunosuppressive drugs (n) & 3 & 4 & 8 \\
\hline
\end{tabular}

${ }^{*}$ RA-NIL = patients who had never received corticosteroids; RA-LOW=patients receiving $<7 \cdot 5$ mg/day prednisone $\bar{乛}$ RA-HIGH=patients receiving $>7.5 \mathrm{mg} /$ day prednisone.

†Values expressed as median (interquartile range) or number (n) of patients.

Table 2 Clinical data for the group with systemic lupus erythematosus

\begin{tabular}{|c|c|c|c|}
\hline Variable & $\begin{array}{l}S L E-N I L^{*} \\
(n=I 1)\end{array}$ & $\begin{array}{l}S L E-L O W^{*} \\
(n=11)\end{array}$ & $\begin{array}{l}S L E-H I G H^{*} \\
(n=14)\end{array}$ \\
\hline Age (years) $\dagger$ & $40(30-60)$ & $41(32-62)$ & $44(33-62)$ \\
\hline Sex distribution $\mathrm{M}: \mathrm{F}$ & $0: 11$ & $2: 9$ & $0: 14$ \\
\hline Disease duration (years) $\dagger$ & $6(2-10)$ & $5(2-14)$ & $16(5-19)$ \\
\hline ARA $\ddagger$ criteria & 6 & 4 & 6 \\
\hline ANA $\ddagger$ titre $\dagger$ & $640(40-640)$ & $160(40-640)$ & $400(40-640)$ \\
\hline Anti-dsDNA (U/ml)† & $24(14-38)$ & $15(3-22)$ & $30(15-68)$ \\
\hline Active disease (n) & 6 & 4 & 9 \\
\hline Immunosuppressive drugs (n) & 0 & 2 & 4 \\
\hline
\end{tabular}

*SLE-NIL=patients who had never received corticosteroids; SLE-LOW=patients receiving prednisolone <7.5 mg/day; SLE-HIGH=patients receiving prednisolone $>7.5 \mathrm{mg} / \mathrm{day}$.

+Values expressed as median (interquartile range) or number ( $n$ ) of patients.

$\ddagger A R A=$ American Rheumatism Association; ANA=antinuclear antibody. 
Rheumatoid patients were assessed for seropositivity, radiological erosions, presence of rheumatoid nodules, and other extra-articular manifestations. The number of active joints areas (swollen and tender) and duration of early morning stiffness were assessed as clinical markers of disease activity. All patients with RA were receiving stable non-steroidal anti-inflammatory drug treatment with or without analgesic drugs, and most rheumatoid patients receiving maintenance corticosteroids were also taking disease modifying drugs, including immunosuppressives. Patients with SLE were clinically and serologically assessed for evidence of disease activity within the preceding three months, according to a composite score of various parameters: group A criteria included active synovitis, cutaneous disease, serositis, pulmonary disease, deteriorating renal function (active urine sediment, proteinuria $>500 \mathrm{mg} / 24 \mathrm{~h}$, falling creatinine clearance), active cerebral disease without other identifiable cause, myositis (proximal limb weakness and raised creatine kinase enzymes or abnormal electromyography), vasculitis, or fever without other identifiable cause; group B criteria included arthralgia, myalgia, neutropenia $<2 \cdot 0 \times 10^{9} / 1$, lymphopenia $<1 \cdot 0 \times 10^{9} / 1$, and hypocomplementaemia. Inactive SLE was defined as none of the above features, whereas active disease was defined as 1 group A criterion or two criteria from group $B$.

Laboratory investigations included plasma viscosity, $\mathrm{C}$ reactive protein, rheumatoid factor assessed by nephelometry (Hyland, normal range 0-40 IU/ml), antinuclear antibodies by immunofluorescence using $\mathrm{HEp}_{2}$ cells, anti-dsDNA by modified Farr assay (Amersham; normal 0-25 U/ml, anticardiolipin antibody binding levels by ELISA, ${ }^{15}$ and immune precipitins to extractable nuclear antigens identified by Ouchterlony immunodiffusion technique or counterimmunoelectrophoresis.

Patients requiring corticosteroids were given the lowest possible maintenance dose to achieve control of the underlying inflammatory disease. The current corticosteroid dose, duration of corticosteroid treatment, and duration of treatment with prednisolone $>7.5 \mathrm{mg} /$ day (a semiquantitative assessment of the need for high maintenance corticosteroid treatment) were analysed. Concurrent disease modifying treatment, including immunosuppressive drugs, was also assessed.

RECOMBINANT HUMAN LI POCORTIN-1

Recombinant human lipocortin-1 was produced in Escherichia coli ${ }^{10}$ and purified (>99\%) by methods described previously. ${ }^{16}$ The purified protein was supplied in $25 \mathrm{mM}$ TRIS-HC1 buffer $\mathrm{pH} 7.7$ with
0.1-5 mM EDTA and $0 \cdot 1 \mathrm{mg} / \mathrm{ml}$ human serum albumin (essentially globulin free). Preparations contained less than $50 \mathrm{pg} / \mathrm{ml}$ endotoxin. $E$ coli of the same strain, but lacking the lipocortin-1-containing plasmid, were processed in parallel using a method identical with that used for recombinant lipocortin-1. This was used in the ELISA as a 'sham' control coating material.

\section{ELISA FOR ANTILIPOCORTIN-1}

ANTIBODIES

Plastic microwell plates (Immulon I, Nunc, Denmark) were coated with $100 \mu \mathrm{l}$ of $0.05 \mathrm{M}$ carbonate-bicarbonate buffer $\mathrm{pH} 9.6$ containing $1 \mu \mathrm{g}$ of recombinant human lipocortin-1 (Biogen Research Corp, Cambridge, Mass, USA) per well at $4^{\circ} \mathrm{C}$ for 18 hours. After a wash phase with carbonate-bicarbonate buffer each well was blocked with $100 \mu \mathrm{l}$ phosphate buffered saline (PBS) pH 7.2 containing $1 \%$ fetal calf serum (Gibco, Paisley, Scotland) for one hour at $37^{\circ} \mathrm{C}$. An optimum range of dilutions of patient $(1: 20-1: 1000)$ and control (1:20) sera in PBS containing $1 \%$ fetal calf serum were then incubated on the plate as were doubling dilutions of a positive serum standard and negative control blank wells. Serum incubation for one hour at $37^{\circ} \mathrm{C}$ was followed by a wash of PBS containing $0.05 \%$ v/v Tween 20 (BDH, Poole, Dorset, England). Each well was subsequently reacted at $37^{\circ} \mathrm{C}$ with $1: 1000$ dilution of rabbit antihuman $\mathrm{IgG}$ or antihuman IgM polyclonal antibody conjugated to alkaline phosphate (Sigma Chemical Co, Poole, Dorset, England). After a further PBS-Tween 20 washing step colour was developed with $5 \mathrm{mg} / \mathrm{ml}$ disodium-nitrophenyl phosphate (Sigma Chemical Co, Poole, Dorset, England) for one hour at $20^{\circ} \mathrm{C}$. Absorbance values at $405 \mathrm{~nm}\left(\mathrm{~A}_{405}\right)$ were obtained with a Dynatech MR580 automated ELISA plate reader, and results were expressed in ELISA units. An ELISA unit was defined by the following equation:

$$
\text { Elisa unit }=\frac{\mathbf{A}_{\mathbf{4 0 5}}(\text { sample }) \times \text { sample dilution }}{\text { reaction vol }(\mathrm{ml})}
$$

A correction was made for day to day variability by assaying positive reference sera with defined activity on each plate.

\section{ELISA VALIDATION}

The specificity of the assay system for detecting antilipocortin-1 antibodies was assessed by the ability of soluble or phospholipid bound lipocortin-1 to compete with plate bound lipocortin-1 for antibody binding. $E$ coli, AB1157 K-12 strain, grown under standard culture conditions and auto- 
claved for 15 minutes at $121^{\circ} \mathrm{C}$ were washed in $10 \mathrm{mM}$ 3-( $N$-morpholino)propanesulphonic acid (MOPS) buffer and resuspended at $1 \times 10^{10} / \mathrm{ml}$ in the same buffer containing sodium azide $1 \mu \mathrm{g} / \mathrm{ml}$ before being coated with $100 \mu \mathrm{g} / \mathrm{ml}$ lipocortin-1 for 30 minutes at $37^{\circ} \mathrm{C}$. In brief, $50 \mu \mathrm{l}$ of optimum dilutions of serum samples containing high levels of IgG or IgM antilipocortin-1 binding were preincubated for 30 minutes at $37^{\circ} \mathrm{C}$ with an equal volume of RPMI 1640 medium $+10 \%$ fetal calf serum containing either $5 \mu \mathrm{g}$ soluble lipocortin- 1 or $5 \times 10^{8}$ lipocortin- 1 coated bacteria. Control absorptions were performed with uncoated cells to determine any nonspecific binding of antibodies to $E$ coli. Serum samples alone, together with those containing soluble lipocortin-1 or supernatants resulting from either one or three absorptions with $E$ coli were then assayed by the ELISA according to the previously described procedure. Table 3 shows the relatively poor competition of soluble lipocortin-1 in fivefold excess for antibody binding to lipocortin-1 absorbed onto plastic. When bound to $E$ coli membranes, however, lipocortin-1 successfully competed for between $46 \%$ and $89 \%$ of antibody binding after three absorptions. Similar results for competition of IgG antilipocortin-1 binding have been obtained be absorbing positive sera with phospholipid micelles. coated with lipocortin-1 (data not shown). This suggests that the antibody binding epitope org lipocortin-1 is most readily expressed when the molecule is bound to membranes or other solido phase matrices.

STATISTICAL METHODS

Clinical and ELISA data were non-parametric and $\vec{P}$ therefore the Mann-Whitney $U$ test was used for intergroup comparisons and the Wilcoxon signew rank test for intragroup significance testing. Corre lation between variables was assessed by the Spearman rank correlation method.

\section{Results}

Control sera from blood donors (median age $3 \mathrm{~B}$ years) and elderly healthy subjects (median age 70 years) were not significantly different in the antilipocortin-1 binding detected: IgM 20 units $/ \mathrm{m}$ (11-30), IgG 13 units/ml (9-28) for healthy controls@

Table 3 Antilipocortin antibody competition

\begin{tabular}{|c|c|c|c|c|c|}
\hline \multirow{2}{*}{$\begin{array}{l}\text { Patient } \\
\text { No }\end{array}$} & \multirow{2}{*}{$\begin{array}{l}\text { Antibody } \\
\text { class }\end{array}$} & \multirow{2}{*}{$\begin{array}{l}\text { Antilipocortin-1 } \\
\text { antibody levels } \\
(\text { ELISA units/ml)* }\end{array}$} & \multirow{2}{*}{$\begin{array}{l}\text { Souble lipocortin-1 } \\
(5 \mu g / \text { well }) \\
(\%) \dagger\end{array}$} & \multicolumn{2}{|c|}{ E coli + lipocortin-1 $(\%) \dagger$} \\
\hline & & & & Absorption 1 & Absorption 3 \\
\hline $\begin{array}{l}1 \\
2 \\
3 \\
4\end{array}$ & $\begin{array}{l}\text { IgG } \\
\text { IgG } \\
\text { IgM } \\
\text { IgM }\end{array}$ & $\begin{array}{l}329 \\
346 \\
465 \\
822\end{array}$ & $\begin{array}{r}2 \\
0 \\
27 \\
23\end{array}$ & $\begin{array}{r}4 \\
27 \\
16 \\
19\end{array}$ & $\begin{array}{l}46 \\
53 \\
51 \\
89\end{array}$ \\
\hline
\end{tabular}

Table 4 Corticosteroid treatment and antilipocortin antibodies. Values are expressed as median (interquartite range)

\begin{tabular}{|c|c|c|c|c|c|}
\hline \multirow[t]{2}{*}{ Groupt } & \multirow[t]{2}{*}{$n$} & \multirow{2}{*}{$\begin{array}{l}\text { Total duration } \\
\text { of disease } \\
\text { (months) }\end{array}$} & \multirow[t]{2}{*}{$\begin{array}{l}\text { Duration of treatment with } \\
\text { prednisdone }>7.5 \mathrm{mg} / \text { day } \\
\text { (months) }\end{array}$} & \multicolumn{2}{|c|}{$\begin{array}{l}\text { Antilipocortin antibodies } \\
\text { (ELISA units } / m l)\end{array}$} \\
\hline & & & & $\operatorname{Ig} M$ & $\operatorname{Ig} G$ \\
\hline Healthy controls & 67 & 0 & $\mathbf{0}$ & $20(11-30)$ & $13(9-28)$ \\
\hline PMR & 26 & $36(12-72)$ & $4(2-8)$ & $25(13-41)$ & $16(9-25)$ \\
\hline COAD & 13 & $60(30-96)$ & $30(12-60)$ & $13(7-24)$ & $26(9-52)$ \\
\hline RA-NIL & 19 & 0 & $\mathbf{0}$ & $27(17-41)$ & $13(6-33)$ \\
\hline RA-LOW & 28 & $68(20-180)$ & $3(0-6)$ & $31(20-57)^{*}$ & $24(15-38)^{*}$ \\
\hline RA-HIGH & 16 & $150(75-228)$ & $15(3-40)$ & $136(42-312)^{* * *}$ & $37(15-50)^{*}$ \\
\hline SLE-NIL & 11 & 0 & 0 & $61(20-118)^{* *}$ & $38(24-62)^{*}$ \\
\hline SLE-LOW & 11 & $23(4-119)$ & $9(3-17)$ & $31(13-67)$ & $16(11-31)$ \\
\hline SLE-HIGH & 14 & $42(24-127)$ & $24(12-30)$ & $95(30-156)^{* * *}$ & $73(36-93)^{*}$ \\
\hline
\end{tabular}

*Higher than healthy controls: ${ }^{*} p<0.05,{ }^{* *} p<0.01,{ }^{* * *} p<0.001$ (Mann-Whitney U test).

$+\mathrm{PMR}=$ polymyalgia rheumatica; $\mathrm{COAD}=$ chronic airways disease; $\mathrm{RA}=$ rheumatoid arthritis; $\mathrm{SLE}=$ systemic lupus erythematosus; NIL LOW, HIGH - see footnotes to Tables 1 and 2. 
and IgM 17 (11-23), IgG 21 (16-25) for elderly controls respectively, expressed as median (interquartile range).

Patient groups with RA (Table 1) were matched for age, sex distribution, active joint inflammation, and the presence of erosive disease, extra-articular manifestations, and rheumatoid factor. Similarly the patient groups with SLE (Table 2) were matched for age, sex distribution and number of American Rheumatism Association criteria. The SLE-NIL and the SLE-HIGH groups had more active disease, however, than the SLE-LOW group. The median age of the group with chronic airways disease (10 men, three women) was 65 years, and the median duration of disease was 24 years (interquartile range 11-35 years). None had an autoimmune disease. The group with polymyalgia rheumatica (five men, 21 women) were older (median age 70 years) and had shorter duration of disease (median three years, interquartile range $2-6$ years).

Despite prolonged corticosteroid treatment in the groups with chronic airways disease and polymyalgia rheumatica (Table 4) and high corticosteroid requirements, particularly in the group with chronic airways disease (median prednisolone dose $15 \mathrm{mg} /$ day), levels of antilipocortin-1 antibodies did not differ from control values (Figs 1,2). Antilipocortin-1 binding levels in RA-NIL patients were also similar to those in healthy controls. Patients with RA taking corticosteroids, however, had significantly increased antilipocortin-1 levels, particularly IgM, notably in the RA-HIGH group. Levels of IgM antilipocortin-1 binding were associated with daily prednisolone dose and with duration of treatment with prednisolone $>7.5 \mathrm{mg} /$ day $(p<0.05)$. Total duration of corticosteroid use was longer in the RA-HIGH group than for the RA-LOW patients (Table 4), but this difference was not statistically significant. There were no correlations between antilipocortin-1 IgM or IgG levels and age, rheumatoid disease activity assessed clinically or biochemically (plasma viscosity, $\mathrm{C}$ reactive protein), or other autoantibodies, including serum rheumatoid factor, antinuclear antibodies, and antidsDNA binding. In addition, the presence of IgM rheumatoid factor in combination with raised levels of IgG antilipocortin-1 was not associated with the presence of high IgM antilipocortin-1 activity. Thus measurement of the latter was not susceptible to interference by rheumatoid factor binding to $\mathrm{IgG}$ antilipocortin-1 in the ELISA assay.

In SLE significantly increased binding of both IgM and IgG antilipocortin-1 antibodies was present not only in the SLE-HIGH group but also in the patients with SLE who had never received corticosteroids (Table 4; Figs 1, 2). Furthermore, raised levels of IgM antilipocortin-1 were significantly associated with inflammatory disease activity $(p<0.01)$ in the overall SLE population. Eighteen patients with SLE with inactive disease had a median IgM antilipocortin-1 level of 27 (interquartile range 16-59) ELISA units/ml, whereas 18 patients with active SLE had a median level of 97 (61-158) $(p<0 \cdot 01$, Mann-Whitney U test). No correlations were detected between antilipocortin-1 antibodies and corticosteroid dosage, disease duration, or serological parameters (antinuclear antibodies, anti-dsDNA, anticardiolipin levels, or immune precipitins to extractable nuclear antigens). Concurrent immunosuppressive or second line agents, including

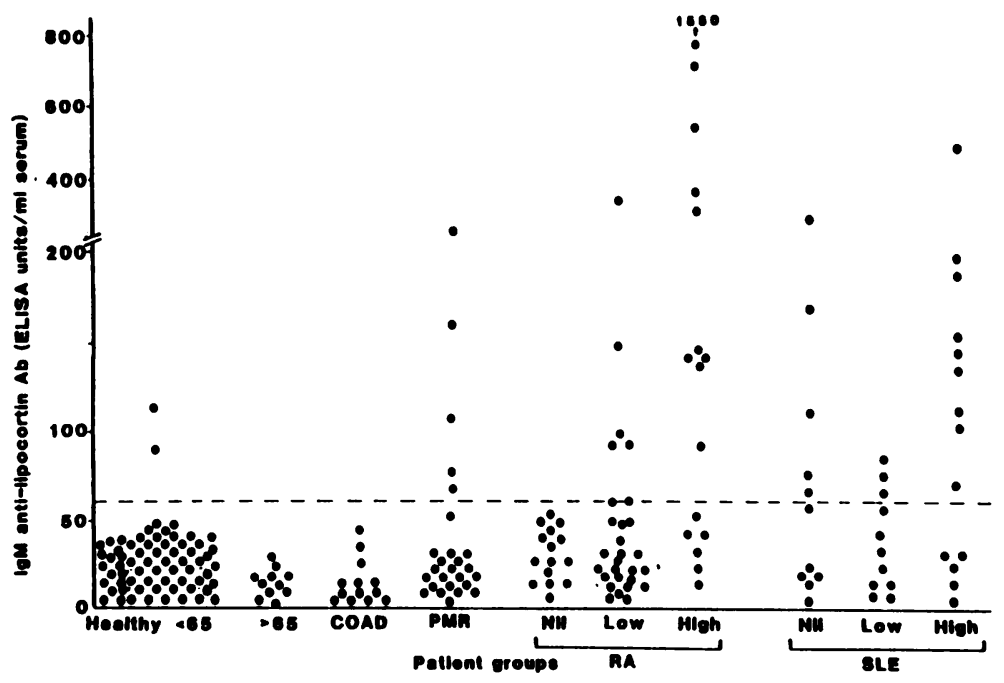

Fig. 1 Serum IgM antilipocortin antibody levels (vertical axis) in patient and control groups (see text). For statistical analysis, see Table 4. $A b=$ antibodies; $C O A D=$ chronic airways disease; $P M R=$ polymyalgia rheumatica; $R A=$ rheumatoid arthritis; $S L E=$ systemic lupus erythematosus. 


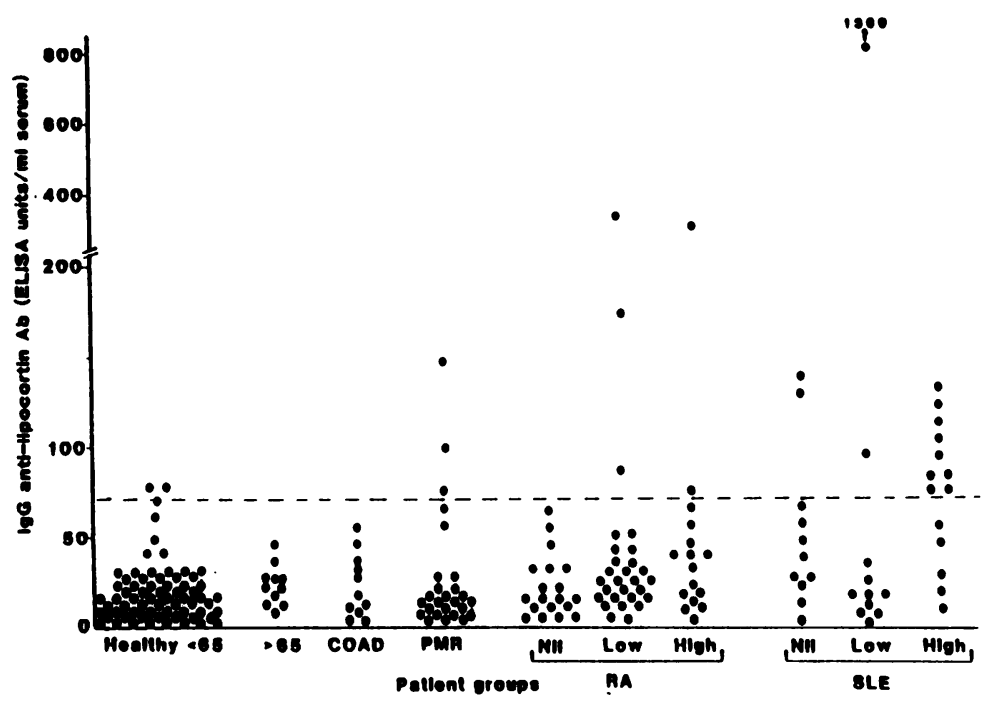

Fig. 2 Serum $\operatorname{IgG}$ antilipocortin antibody levels (vertical axis) in patient and control groups (see text). For statistical analysis, see Table 4. $A b=$ antibodies; $C O A D=$ chronic airways disease; $P M R=$ polymyalgia rheumatica; $R A=$ rheumatoid arthritis; $S L E=$ systemic lupus erythematosus.

azathioprine, D-penicillamine, or gold, did not affect antilipocortin-1 antibody levels in patients with either RA or SLE.

\section{Discussion}

In patients with RA a striking association was found between raised IgM (and less dramatically IgG) antilipocortin-1 autoantibody levels and prolonged, high dose corticosteroid treatment. This association may be due to two related phenomena. Firstly, subsets of patients with RA have been shown to have enhanced phospholipase $A_{2}$ activity in peripheral blood mononuclear cells, ${ }_{17}$ increased prostanoid release from monocytes, ${ }^{18}$ greater circulating numbers of activated HLA-DR ${ }^{+}$monocytes, ${ }^{19}$ and enhanced spontaneous immunoglobulin production..$^{20}$ These features seem to be independent of drug treatment and indicate a 'primed' immune system in some patients with RA. This may result in presentation of increased amounts of self antigens, such as steroid induced lipocortin-1, with stimulation of autoantibody formation. Secondly, the type of corticosteroid presentation is also probably important as short duration corticosteroid treatment may reduce serum immunoglobulin concentrations, whereas chronic oral prednisolone may enhance spontaneous immunoglobulin synthesis. ${ }^{22} 23$ Thus repetitive antigen challenge may lead to the generation of high levels of autoantibodies directed against lipocortin-1. We considered that active RA alone was insufficient to account for raised antilipocortin-1 levels as the occurrence of high antilipocortin-1 antibody levels in steroid treated patients with RA was independent of age, active synovitis, and extra $\frac{0}{8}$
articular disease manifestations.

In contrast with RA, raised IgM antilipocortin levels in SLE were associated with active inflacino matory disease and were independent of co $\mathrm{i}:-$ costeroid treatment. When inflammatory features SLE were controlled by corticosteroids lowes binding levels similar to background control value resulted. The different pattern of autoantibodfo responses between RA and SLE patient groups may reflect important differences in disease expression $\overrightarrow{0}$ with more widespread fundamental alterations of immune regulation occurring in active SLE. ${ }^{24}$ Although our present findings confirm those of Hirata et $a l,{ }^{9}$ there are several important difo ferences. Firstly, the strong association between antilipocortin-1 antibodies and corticosteroid treat 3 ment was not found by Hirata $e$ al in six rheumatois, patients who had such antibodies detected by bioassay methods. This discrepancy may result from the small number of serum samples analysed by these authors. Secondly, the present ELISA methot allows quantitative assessment of antibody levels whereas the bioasssays used previously may haveु been less sensitive; the ELISA method may allowe better discrimination between individual patient with RA receiving corticosteroid treatment.

The class of antilipocortin-1 antibody binding wa? predominantly IgM in both RA and SLE. There was no correlation, however, between antilipocortin-\$ antibody levels and anti-dsDNA, antinuclear' antibodies, anticardiolipin antibody levels, of immune precipitins to extractable nuclear antigen in SLE, nor was there any correlation with serure 
rheumatoid factor in RA. This confirms earlier work $^{9}$ and suggests that IgM and IgG antilipocortin1 antibodies are distinct autoantibodies. The reasons for the predominant IgM response are unclear but may be related to repetitive antigen challenge, resulting in repeated synthesis of primary IgM class autoantibodies. Alternatively chronic prednisolone treatment itself may be relevant to this phenomenon as it has been shown to potentiate the primary immune response to keyhole limpet haemocyanin immunisation. ${ }^{26}$

Despite prolonged, high dose maintenance corticosteroid treatment in chronic airways disease (and in polymyalgia rheumatica) these patients did not have raised levels of antilipocortin-1 antibodies (Table 4). This suggests that other mechanisms are responsible for corticosteroid resistant asthma. ${ }^{14}$ Recent evidence suggests that defective monocyte responsiveness to corticosteroids may be important in reducing their therapeutic effect in these asthmatic patients. ${ }^{27} 28$ These observations, together with normal antilipocortin-1 autoantibody levels in steroid treated patients with polymyalgia rheumatica, indicate that the nature of the underlying autoimmune disorder is important in the generation of such autoantibodies.

We suggest that antilipocortin-1 antibodies are clinically significant in patients with RA by impairing the lipocortin-1 mediated inhibition of phospholipase $A_{2}$ activity. This would result in a functional corticosteroid insufficiency with an increased corticosteroid requirement and thus relative 'steroid resistance'. Evidence supporting a functional role for these antibodies includes work by Hirata et al, ${ }^{9}$ who showed that antilipocortin-1 antibodies potentiated phospholipase $\mathrm{A}_{2}$ activity and enhanced the stimulatory activity of bradykinin on the release of arachidonic acid in vitro, whereas addition of purified lipocortin-1 overcame these effects. This work, together with observations of enhanced phospholipase $A_{2}$ activity ${ }^{17}$ and increased prostanoid release in RA peripheral blood monocytes, ${ }^{18}$ suggests that antilipocortin-1 autoantibodies may have important functions in RA inflammatory processes and immune phenomena. Longitudinal studies are in progress to examine autoantibody induction at the start of corticosteroid treatment in patients with RA, as well as the relation between IgM antilipocortin-1 antibody levels and disease activity in SLE. This information may lead to better use of corticosteroids in the treatment of these diseases.

This project was carried out with support from the Arthritis and Rheumatism Council (for NJG) and the Sidney Robinson Trust (for MRP). We are grateful to Mr I James, Royal United Hospital Immunology Laboratory, for performing antinuclear antibody, anti-DNA binding, and serum rheumatoid factor analyses, to $\operatorname{Dr} \mathrm{N}$ McHugh for anticardiolipin antibody estimations, to Dr C Higgs MRCP, Royal United Hospital, Bath, for providing patients with reversible chronic airways disease, and to D Pratt and L Sinclair of Biogen for work with the recombinant proteins.

\section{References}

1 Di Rosa M, Flower R J, Hirata F, Parente L, Russo-Marie F. Nomenclature announcement. Anti-phospholipase proteins. Prostaglandins 1984; 28: 441-2.

2 Hirata F, Schiffman E, Venkatasubramanian K, Salomon D, Axelrod $\mathbf{J}$. A phospholipase $\mathbf{A}_{2}$ inhibitory protein in rabbit neutrophils induced by glucocorticoids. Proc Natl Acad Sci USA 1980; 77: 2533-6.

3 Blackwell G J, Carnuccio R, DiRosa M, Flower R J, Parente L, Persico P. Macrocortin: a polypeptide causing the antiphospholipase effect of glucocorticoids. Nature 1980; 287: 147-9.

4 Flower R J. Macrocortin and the antiphospholipase proteins. In: Weissmann G. Advances in inflammation research. Vol 8. New York: Raven Press, 1984: 1-34.

5 Davidson F F, Dennis E H, Powell M, Glenney J R Jr. Inhibition of phospholipase $A_{2}$ by 'lipocortins' and calpactins. An effect of binding to substrate phospholipids. J Biol Chem 1987; 262: 1698-705.

6 Pepinsky R B, Tizard R, Mattaliano R J, et al., Five distinct calcium and phospholipid binding proteins share homology with lipocortin-1. J Biol Chem 1988; 263: 10799-811.

7 Slocumb C H. Relative cortisone deficiency simulating exacerbation of arthritis. Bull Rheum Dis 1952; 3: 21-2.

8 Rotstein J, Good R A. Steroid pseudorheumatism. Arch Intern Med 1957; 99: 545-5.

9 Hirata F, del Carmine R, Nelson C A, et al. Presence of autoantibody for phospholipase inhibitory protein, lipomodulin, in patients with rheumatic diseases. Proc Natl Aca Sci USA 1981; 78: $3190-4$.

10 Wallner B P, Mattaliano R J, Hession C, et al. Cloning and expression of human lipocortin, a phospholipase $\mathrm{A}_{2}$ inhibitor with potential anti-inflammatory activity. Nature 1986; 320: $77-81$.

11 Ropes M W, Bennett G A, Cobb S, Jacox R, Jessar R A. 1958 revision of diagnostic criteria for rheumatoid arthritis. Bull Rheum Dis 1958; 9: 175-6.

12 Tan E M, Cohen A S, Fries J F, et al. The 1982 revised criteria for the classification of systemic lupus erythematosus. Arthritis Rheum 1982; 25: 1271-7.

13 Bird H A, Esselinckx W, Dixon A S, Mowat A G, Wood P H N. An evaluation of criteria for polymyalgia rheumatica. Ann Rheum Dis 1979; 28: 434-9.

14 Carmichael J, Paterson I C, Diaz P, Crompton G K, Kay A B, Grant I W B. Corticosteroid resistance in chronic asthma. Br Med J 1981; 282: 1419-22.

15 Harris E N, Gharavi A E, Patel S P, Hughes G R V. Evaluation of the anti-cardiolipin antibody test: report of an international workshop held 4 April 1986. Clin Exp Immunol 1987; 68: 215-22.

16 Pepinsky R B, Sinclair L K, Browning J L, et al. Purification and partial sequence analysis of a 37-kDa protein that inhibits phospholipase $\mathrm{A}_{2}$ activity from rat peritoneal exudates. $J$ Biol Chem 1986; 261: 4239-46.

17 Bomalaski J S, Clark M A, Zurier R B. Enhanced phospholipase activity in peripheral blood monocytes from patients with rheumatoid arthritis. Arthritis Rheum 1986; 29: 313-8.

18 Seitz M, Hunstein W. Enhanced prostanoid release from monocytes of patients with rheumatoid arthritis and active systemic lupus erythematosus. Ann Rheum Dis 1985; 44: 438-45. 
850 Goulding, Podgorski, Hall, et al

19 Haraoui B, Wilder R L, Malone D G, Allen J B, Katona I M, Wahl S M. Immune function in severe rheumatoid arthritis: a relationship between peripheral blood mononuclear cell proliferation to soluble antigens and mononuclear cell subset profiles. J Immunol 1984; 133: 697-701.

20 Smiley J D, Sachs C, Ziff $M$. In vitro synthesis of immunoglobulin by rheumatoid synovial membrane. J Clin Invest 1968; 47: 624-32.

21 Doekes G, Westedt M L, de Rooy-Dijk H H, Daha M R, de Vries E, Cats A. Spontaneous immunoglobulin synthesis by peripheral mononuclear cells in active rheumatoid arthritis. Rheumatol Int 1986; 6: 263-8.

22 Cupps T R, Edgar L C, Thomas C A, Fauci A S. Multiple mechanisms of $B$ cell immunoregulation in man after administration of in vitro corticosteroids. J Immunol 1984; 132: 170-5.

23 Griggs R C, Condemi J J, Vaughan J H. Effect of therapeutic dosages of prednisone on human immunoglobulin $G$ metabolism. J Allergy Clin Immunol 1972; 49: 267-73.
24 Holman H R. Systemic lupus erythematosus. In: Samter M, ed. Immunological diseases. 2nd ed. Boston: Little, Brown, 1971: 995-1013.

25 Miescher P A, Rothfield N, Miescher A. Immunologic phenomena in patients with systemic lupus erythematosus. In: $\bar{c}$ Dubois E L, ed. Lupus erythematosus. 2nd ed. Los Angeles: University of Southern California Press, 1974: 153-90.

26 Tuchinda M, Newcomb $R$ W, DeVald B L. Effect of $\stackrel{\bar{O}}{-}$ prednisone treatment on the human immune response to $\frac{\rho}{\partial}$ keyhole limpet hemocyanin. Int Arch Allergy 1972; 42: 533-44.

27 Poznansky M C, Gordon A C H, Grant I W B, Wyllie A H. A心ّ̂ cellular abnormality in glucocorticoid resistant asthma. Clin $\rightarrow$ Exp Immunol 1985; 61: 135-42.

28 Poznansky M C, Gordon A C H, Douglas J G, Krajewski A S, Wyllie A H, Grant I W B. Resistance to methylprenisolone in cultures of blood mononuclear cells from glucocorticoidresistant asthmatic patients. Clin Sci 1984; 67: 639-45. 